NASA/TM-2002-211324

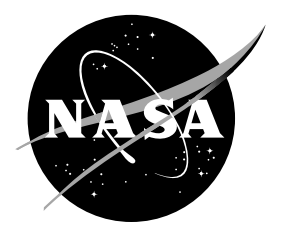

Numerical Investigation of "Transonic Resonance" With a ConvergentDivergent Nozzle

Ching Y. Loh

Taitech Inc., Cleveland, Ohio

K.B.M.Q. Zaman

Glenn Research Center, Cleveland, Ohio 
Since its founding, NASA has been dedicated to the advancement of aeronautics and space science. The NASA Scientific and Technical Information (STI) Program Office plays a key part in helping NASA maintain this important role.

The NASA STI Program Office is operated by Langley Research Center, the Lead Center for NASA's scientific and technical information. The NASA STI Program Office provides access to the NASA STI Database, the largest collection of aeronautical and space science STI in the world. The Program Office is also NASA's institutional mechanism for disseminating the results of its research and development activities. These results are published by NASA in the NASA STI Report Series, which includes the following report types:

- $\quad$ TECHNICAL PUBLICATION. Reports of completed research or a major significant phase of research that present the results of NASA programs and include extensive data or theoretical analysis. Includes compilations of significant scientific and technical data and information deemed to be of continuing reference value. NASA's counterpart of peerreviewed formal professional papers but has less stringent limitations on manuscript length and extent of graphic presentations.

- $\quad$ TECHNICAL MEMORANDUM. Scientific and technical findings that are preliminary or of specialized interest, e.g., quick release reports, working papers, and bibliographies that contain minimal annotation. Does not contain extensive analysis.

- CONTRACTOR REPORT. Scientific and technical findings by NASA-sponsored contractors and grantees.
- CONFERENCE PUBLICATION. Collected papers from scientific and technical conferences, symposia, seminars, or other meetings sponsored or cosponsored by NASA.

- SPECIAL PUBLICATION. Scientific, technical, or historical information from NASA programs, projects, and missions, often concerned with subjects having substantial public interest.

- TECHNICAL TRANSLATION. Englishlanguage translations of foreign scientific and technical material pertinent to NASA's mission.

Specialized services that complement the STI Program Office's diverse offerings include creating custom thesauri, building customized data bases, organizing and publishing research results ... even providing videos.

For more information about the NASA STI Program Office, see the following:

- Access the NASA STI Program Home Page at http://www.sti.nasa.gov

- E-mail your question via the Internet to help@sti.nasa.gov

- Fax your question to the NASA Access Help Desk at 301-621-0134

- Telephone the NASA Access Help Desk at 301-621-0390

- Write to:

NASA Access Help Desk

NASA Center for AeroSpace Information 7121 Standard Drive

Hanover, MD 21076 
NASA/TM-2002-211324

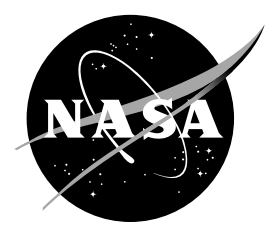

Numerical Investigation of "Transonic Resonance" With a ConvergentDivergent Nozzle

Ching Y. Loh

Taitech Inc., Cleveland, Ohio

K.B.M.Q. Zaman

Glenn Research Center, Cleveland, Ohio

Prepared for the

40th Aerospace Sciences Meeting and Exhibit

sponsored by the American Institute of Aeronautics and Astronautics

Reno, Nevada, January 14-17, 2002

National Aeronautics and

Space Administration

Glenn Research Center 


\section{Acknowledgments}

This work was supported by the Supersonic Propulsion Technology Program of NASA Glenn Research

Center. The authors are grateful to Dr. Nicholas Georgiadis for reviewing the manuscript.

This report is a preprint of a paper intended for presentation at a conference. Because of changes that may be made before formal publication, this preprint is made available with the understanding that it will not be cited or reproduced without the permission of the author.

Available from

NASA Center for Aerospace Information 7121 Standard Drive

Hanover, MD 21076
National Technical Information Service 5285 Port Royal Road Springfield, VA 22100 


\title{
NUMERICAL INVESTIGATION OF 'TRANSONIC RESONANCE' WITH A CONVERGENT-DIVERGENT NOZZLE
}

\author{
Ching Y. Loh and K.B.M.Q. Zaman \\ National Aeronautics and Space Administration \\ Glenn Research Center \\ Cleveland, Ohio 44135
}

\begin{abstract}
At pressure ratios lower than the design value, convergent-divergent (C-D) nozzles often undergo a flow resonance accompanied by the emission of acoustic tones. The phenomenon, driven by the unsteady shock within the divergent section of the nozzle, has been studied experimentally by Zaman et al[1]. In this paper, the space-time conservation element solution element $(\mathrm{CE} / \mathrm{SE})$ method $[2,3,4]$ is employed to numerically investigate the phenomenon. The computations are performed for a given nozzle geometry for several different pressure ratios. Sustained 'limit cycle' oscillations are encountered in all cases. The oscillation frequencies, their variation with pressure ratio including a 'stage jump', agree well with the experimental results. The unsteady flow data confirm that stage 1 of the resonance (fundamental) involves a one-quarter standing wave while stage 2 (third harmonic) involves a three-quarter standing wave within the divergent section of the nozzle. Details of the shock motion, and the flow and near acoustic field, are documented for one case each of stages 1 and 2.
\end{abstract}

\section{Introduction}

This paper concerns an aeroacoustic resonance often encountered with convergent-divergent nozzles when run near 'transonic' conditions. The resonance is usually accompanied by the emission of intense acoustic tones. While a casual observer may easily confuse it with the well-known 'screech tone', it has been shown to be different in character as well as origin. The frequency of the tone increases with increasing plenum pressure. The frequency variation may involve a staging behavior, i.e., an abrupt jump in frequency. While odd harmonic stages take place at lower pressures, the fundamental takes place over a wide range of higher pressures. Depending on nozzle geometry, the fundamental has been found to persist to pressure ratios as high as 5 . The phenomenon has been identified and studied experimentally by Zaman et al [1]. For a discussion of background, technological relevance, and pertinent past work from the literature, the reader is referred to the cited reference. A discussion of numerical works from the literature apparently capturing the same phenomenon, and the implication of those results, will be deferred to the concluding remarks in Section 5.

During the course of the experimental study a numerical study was initiated to complement the investigation. The 'CE/SE' method, to be elaborated shortly, was employed because of its past success with flows involving shocks and acoustic waves [5]. The calculations were first performed for a nozzle geometry and pressure ratio that corresponded to an experimental test condition. The result was encouraging in that the flow not only exhibited a quasi-periodicity but the frequency was also in agreement with the experimental result. Subsequent calculations at two other pressures captured the right trend in the frequency variation as well as the stage-jump. These promising results prompted a further study. This was deemed well-justified not only to shed further light on the mechanism of the phenomenon but also to gain confidence in the CFD methodology.

The 'Space-Time Conservation-Element and Solution-Element (CE/SE) Method' [2,3,4] was used as a numerical platform in the study. As demonstrated in previous papers, the CE/SE method is well suited for computing waves in compressible shear flows [5] as well as vorticity/shock interactions [6], both being pertinent in the phenomenon under consideration. Furthermore, based on the novel CE/SE non-reflecting boundary conditions (NRBC), it is expected that a small near field computational domain would be sufficient and the simulation could be focused on the region of most importance in the resonance. 
The objective of this paper is to describe the key results of the numerical study. The paper is arranged as follows. The axisymmetric CE/SE scheme with an unstructured-grid is discussed in Section 2. The initial and boundary conditions as well as the CE/SE NRBC are discussed in section 3 . The numerical results are presented and compared with experimental results in Section 4 , further discussion and summary are given in Section 5.

\section{The Unstructured Axisymmetric CE/SE Euler and Navier-Stokes Solvers}

In this section the CE/SE numerical scheme is summarized including (a) the Navier-Stokes CE/SE solver, (b) the unstructured grid used, and (c) the treatment of the source term and the 2-D axisymmetric approximation of LES (large eddy simulation) applied to the jet flow. The basic CE/SE principle and details of the Euler schemes can be found in the cited original papers [2, 3, 4].

\subsection{Conservation Form of the Unsteady Axisymmetric Navier-Stokes Equations}

In general, the CE/SE method systematically solves a set of integral equations derived directly from the physical conservation laws, and hence naturally captures shocks and other discontinuities in the flow. Both dependent variables and their derivatives are solved for simultaneously and, consequently, the flow vorticity can be obtained without reduction in accuracy. Non-reflecting boundary conditions (NRBCs) are also easily implemented because of the flux-conservation formulation.

Consider a dimensionless conservation form of the unsteady axisymmetric Navier-Stokes equations of a perfect gas. Let $\rho, u, v, p$, and $\gamma$ be the density, streamwise velocity component, radial velocity component, static pressure, and constant specific heat ratio, respectively. The axisymmetric Navier-Stokes equations then can be written in the following vector form:

$$
\boldsymbol{U}_{t}+\boldsymbol{F}_{x}+\boldsymbol{G}_{y}=\boldsymbol{Q}
$$

where $x, y \geqslant 0$, and $t$ are the streamwise and radial coordinates and time, respectively. The conservative flow variable vector $\boldsymbol{U}$ and the flux vectors in the streamwise and radial directions, $\boldsymbol{F}$ and $\boldsymbol{G}$, are given by:

$$
\boldsymbol{U}=\left(\begin{array}{c}
U_{1} \\
U_{2} \\
U_{3} \\
U_{4}
\end{array}\right), \quad \boldsymbol{F}=\left(\begin{array}{c}
F_{1} \\
F_{2} \\
F_{3} \\
F_{4}
\end{array}\right), \quad \boldsymbol{G}=\left(\begin{array}{c}
G_{1} \\
G_{2} \\
G_{3} \\
G_{4}
\end{array}\right)
$$

with

$$
\begin{gathered}
U_{1}=\rho, \quad U_{2}=\rho u, \quad U_{3}=\rho v, \\
U_{4}=p /(\gamma-1)+\rho\left(u^{2}+v^{2}\right) / 2 .
\end{gathered}
$$

The flux vectors are further split into inviscid and viscous fluxes:

$$
\mathbf{F}=\mathbf{F}_{\mathbf{i}}-\mathbf{F}_{\mathbf{v}}, \mathbf{G}=\mathbf{G}_{\mathbf{i}}-\mathbf{G}_{\mathbf{v}}
$$

where the inviscid fluxes are the same as in the Euler equations:

$$
\begin{gathered}
F_{i 1}=U_{2}, \\
F_{i 2}=(\gamma-1) U_{4}+\left[(3-\gamma) U_{2}^{2}-(\gamma-1) U_{3}^{2}\right] / 2 U_{1}, \\
F_{i 3}=U_{2} U_{3} / U_{1}, \\
F_{i 4}=\gamma U_{2} U_{4} / U_{1}-(\gamma-1) U_{2}\left[U_{2}^{2}+U_{3}^{2}\right] / 2 U_{1}^{2}, \\
G_{i 1}=U_{3}, \quad G_{i 2}=U_{2} U_{3} / U_{1}, \\
G_{i 3}=(\gamma-1) U_{4}+\left[(3-\gamma) U_{3}^{2}-(\gamma-1) U_{2}^{2}\right] / 2 U_{1}, \\
G_{i 4}=\gamma U_{3} U_{4} / U_{1}-(\gamma-1) U_{3}\left[U_{2}^{2}+U_{3}^{2}\right] / 2 U_{1}^{2},
\end{gathered}
$$

and the viscous fluxes are:

$$
\begin{gathered}
F_{v 1}=0, \quad F_{v 2}=\mu\left(2 u_{x}-\frac{2}{3} \nabla \cdot \mathbf{V}\right), \\
F_{v 3}=\mu\left(v_{x}+u_{y}\right), \\
F_{v 4}=\mu\left[2 u u_{x}+\left(u_{y}+v_{x}\right) v-\frac{2}{3}(\nabla \cdot \mathbf{V}) u+\right. \\
\left.\frac{\gamma}{\operatorname{Pr}} \frac{\partial}{\partial y}\left(\frac{U_{4}}{U_{1}}-\frac{u^{2}+v^{2}}{2}\right)\right] \\
G_{v 1}=0, \quad G_{v 2}=\mu\left(v_{x}+u_{y}\right), \\
G_{v 3}=\mu\left(2 v_{y}-\frac{2}{3} \nabla \cdot \mathbf{V}\right), \\
G_{v 4}=\mu\left[2 v v_{y}+\left(u_{y}+v_{x}\right) u-\frac{2}{3}(\nabla \cdot \mathbf{V}) v+\right. \\
\left.\frac{\gamma}{\operatorname{Pr}} \frac{\partial}{\partial y}\left(\frac{U_{4}}{U_{1}}-\frac{u^{2}+v^{2}}{2}\right)\right]
\end{gathered}
$$

where $u, v, u_{x}, u_{y}, v_{x}, v_{y}$ are respectively the $x-$ and $y-$ flow velocity components and their derivatives. They can be written in terms of the conservative variables $U_{1}, U_{2}, U_{3}$ and $U_{4} . \operatorname{Pr}$ is the Prandtl number, and $\mu$ the viscosity. The velocity divergence

$$
\nabla \cdot \mathbf{V}=u_{x}+v_{y}+v / y .
$$

The right hand source term $\boldsymbol{Q}$ is the same as in the axisymmetric Euler equations [7]:

$$
Q=\left(\begin{array}{l}
Q_{1} \\
Q_{2} \\
Q_{3} \\
Q_{4}
\end{array}\right)
$$

where

$$
\begin{gathered}
Q_{1}=-U_{3} / y, \quad Q_{2}=-U_{2} U_{3} / U_{1} y \\
Q_{3}=-U_{3}^{2} / U_{1} y, \quad Q_{4}=-G_{4} / y
\end{gathered}
$$

By considering $(x, y, t)$ as coordinates of a threedimensional Euclidean space $E_{3}$ and using Gauss' divergence theorem, it follows that Eq. (1) is equivalent to the following integral conservation law:

$$
\oint_{S(V)} \boldsymbol{H}_{m} \cdot \mathrm{d} \mathbf{S}=\int_{V} Q_{m} \mathrm{~d} V, \quad m=1,2,3,4
$$

where $S(V)$ denotes the surface around a volume $V$ in $E_{3}$ and $\boldsymbol{H}_{m}=\left(F_{m}, G_{m}, U_{m}\right)$. 


\subsection{Unstructured Grid for CE/SE}

The CE/SE scheme is naturally adapted to unstructured triangular grid. The unstructured version of the CE/SE scheme can be briefly described using Fig. 1. Here, $\triangle A B C$ is a typical triangular cell centered at $O$, and $D, E, F$ are the centers of the neighboring triangular cells where the flow data at the previous time step are given. Each triangle center and its three neighboring triangle centers form three cylindrical quadrilateral conservation elements or $C E \mathrm{~s}$, as shown in Fig. 1. In the space-time $E_{3}$ space, (2) is applied to the hexagon cylinder $A D B E C F$ ( the volume $V$ ) that consists of these 3 quadrilateral $C E$ s. The discrete approximation of (2) is then

$$
\oint_{S(V)} \boldsymbol{H}_{m} \cdot \mathrm{d} \mathbf{S}=V\left(Q_{m}\right)_{j}^{n+1}
$$

for $m=1,2,3,4$, where $\boldsymbol{H}_{m}^{*}=\left(F_{m}^{*}, G_{m}^{*}, U_{m}^{*}\right)$. The right-hand side of (3), in general, is the volume $V$ times the 'source' term evaluated at an appropriate gaussian quadrature node. Here, the gaussian quadrature node is the center of the hexagon $A D B E C F$ at the new time level.

In the CE/SE scheme, the above flux conservation relation (2) in space-time is the only mechanism that transfers information between node points. A conservation element $C E$ (here, quadrilateral cylinders) is the finite volume to which (2) is applied. Discontinuities are allowed to occur in the interior of a conservation element. A solution element $S E$ associated with a grid node (e.g., $D, E, F$ in Fig. 1) is here a set of interface planes in $E_{3}$ that passes through this node (e.g. $D A A^{\prime} D^{\prime}, D B B^{\prime} D^{\prime}, E B B^{\prime} E^{\prime}, E C C^{\prime} E^{\prime}$, etc. ).

At time level $n$, the solution variables $\boldsymbol{U}, \boldsymbol{U}_{x}$, and $\boldsymbol{U}_{y}$ are given at these three nodes. We are to solve $\boldsymbol{U}, \boldsymbol{U}_{x}$ and $\boldsymbol{U}_{y}$ at $O^{\prime}$ at the new time level $n+1$.

In principle, each of the $3 C E$ s provides 4 scalar equations when (2) is applied to it. There are totally 12 scalar equations for the 12 scalar unknowns at $O^{\prime}$. The problem is solvable. All the unknowns are solved for based on these relations. No extrapolations (interpolations) across a stencil of cells are needed or allowed. But in reality, $\boldsymbol{U}$ at the hexagon center at the new time level $n+1$ is first evaluated from (3) and then by Taylor expansion, $\boldsymbol{U}$ at the center $O^{\prime}$ of triangle $A B C$ can be obtained. Consequently, $\boldsymbol{U}_{x}$ and $\boldsymbol{U}_{y}$ are solved with the necessary numerical dissipation added. Details can be found in [4].

An important issue is how to accurately calculate the surface fluxes of the $S E$ s. For this purpose, within a given solution element $S E(j, n)$, where $j, n$ are the node index, and time step respectively, the flow variables are not only considered continuous but are also approximated by linear Taylor expansions:

$$
\boldsymbol{U}^{*}(x, y, t ; j, n)=\boldsymbol{U}_{j}^{n}+\left(\boldsymbol{U}_{x}\right)_{j}^{n}\left(x-x_{j}\right)+
$$

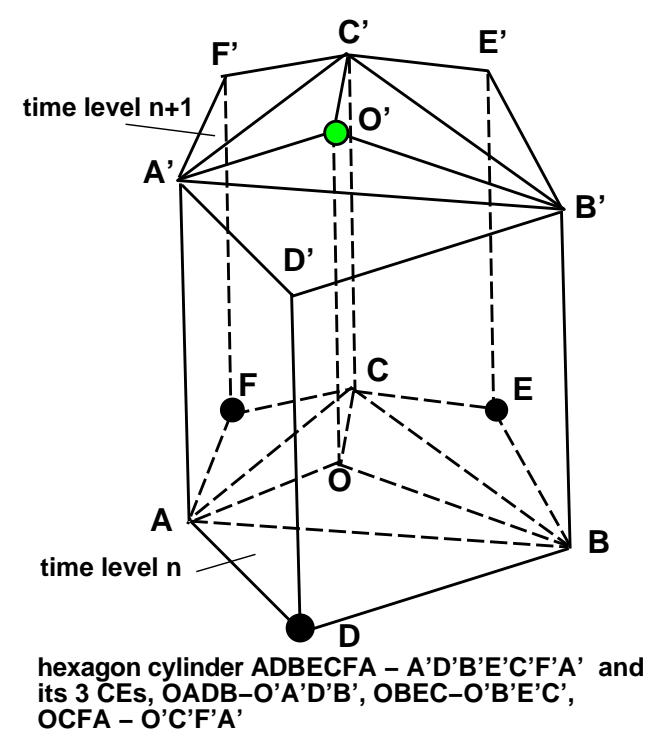

Figure 1: CE/SE unstructured grid

$$
\begin{gathered}
\left(\boldsymbol{U}_{y}\right)_{j}^{n}\left(y-y_{j}\right)+\left(\boldsymbol{U}_{t}\right)_{j}^{n}\left(t-t^{n}\right), \\
\boldsymbol{F}^{*}(x, y, t ; j, n)=\boldsymbol{F}_{j}^{n}+\left(\boldsymbol{F}_{x}\right)_{j}^{n}\left(x-x_{j}\right)+ \\
\left(\boldsymbol{F}_{y}\right)_{j}^{n}\left(y-y_{j}\right)+\left(\boldsymbol{F}_{t}\right)_{j}^{n}\left(t-t^{n}\right), \\
\boldsymbol{G}^{*}(x, y, t ; j, n)=\boldsymbol{G}_{j}^{n}+\left(\boldsymbol{G}_{x}\right)_{j}^{n}\left(x-x_{j}\right)+ \\
\left(\boldsymbol{G}_{y}\right)_{j}^{n}\left(y-y_{j}\right)+\left(\boldsymbol{G}_{t}\right)_{j}^{n}\left(t-t^{n}\right),
\end{gathered}
$$

where $j$ is the node index of $D, E$ or $F$. The partial derivatives of $\boldsymbol{F}$ and $\boldsymbol{G}$ can be related to the corresponding derivatives of $\boldsymbol{U}$ by using the chain rule, and $\boldsymbol{U}_{t}$ can be obtained from (1). Now, the surface flux can be calculated accurately by first evaluating the flux vectors at the geometrical center of the surface through the Taylor expansions (4-6). With unstructured grids, the CE/SE procedure is simplified and more adapted to complicated geometry. Only a single set of mesh points is needed as compared to the spatially staggered mesh for structured grids and the time-marching is completed in one step rather than two. Also, the simple non-reflecting boundary conditions described previously [5 - 8] still work well with an unstructured grid. More details about the unstructured CE/SE method can be found in [4]. The weighted $a-\epsilon \mathrm{CE} / \mathrm{SE}$ scheme is used here.

\subsection{Treatment of the Source Term}

The treatment is identical to the one used in [7] and is briefly reiterated here. As the source term $Q=Q(U)$ itself is a function of the unknown $\boldsymbol{U}$ at the new time level, a local iterative procedure is needed to determine $\boldsymbol{U}$. The discretized integral equation (3) reduces to the form

$$
\boldsymbol{U}-\boldsymbol{Q}(U) \Delta t=\boldsymbol{U}_{H},
$$


where $\boldsymbol{U}_{H}$ is the local homogeneous solution (i.e. the solution for $\boldsymbol{Q}=0$ locally). Note that $\boldsymbol{U}_{H}$ only depends on the solution at the previous time step, i.e. $\boldsymbol{U}_{H}$ is obtained using explicit formulas. A Newton iterative procedure to determine $\boldsymbol{U}$ is then

$$
\boldsymbol{U}^{(i+1)}=\boldsymbol{U}^{(i)}-\left(\frac{\partial \boldsymbol{\Phi}}{\partial \boldsymbol{U}}\right)^{-1}\left[\boldsymbol{\Phi}\left(\boldsymbol{U}^{(i)}\right)-\boldsymbol{U}_{H}\right],
$$

where $i$ is the iteration number and

$$
\boldsymbol{\Phi}(\boldsymbol{U})=\boldsymbol{U}-\boldsymbol{Q}(\boldsymbol{U}) \Delta t
$$

Normally, $\boldsymbol{U}$ at the previous time step is a good initial guess $\mathbf{U}^{(\mathbf{0})}$ and the procedure takes about 2-3 iterations to convergence.

\subsection{Large Eddy Simulation (LES)}

A simplified LES procedure similar to those used in [9] is adopted here to account for the strong momentum exchange in the jet shear layer outside the nozzle. In this 2-D approximation of LES, a simple Smagorinsky's subgrid scale model is used for the eddy viscosity:

$$
\mu_{t}=\left(C_{s} \Delta\right)^{2}\left(2 S_{i j} S_{i j}\right)^{1 / 2},
$$

where

$$
S_{i j}=\frac{1}{2}\left(\frac{\partial u_{i}}{\partial x_{j}}+\frac{\partial u_{j}}{\partial x_{i}}\right),
$$

$\Delta=(\Delta x \Delta y)^{1 / 2}, \quad C_{s}=0.1$. Then $\mu_{t}+\mu$ repalces $\mu$ in the Navier-Stokes CE/SE solver.

\section{Computational Domain, Initial and Boundary Conditions}

As stated earlier, an axisymmetric 2-D CE/SE NavierStokes solver was used. It should be noted that 'high Reynolds number', 'inviscid' calculations were first performed for the nozzle internal flow (that is, $\mu$ was set to zero for the viscous flux terms in the governing equations, Section 2). With a uniform flow at the nozzle inlet and no-slip condition on the wall, trunction and other errors in the numerical process imposed a viscous effect and there was a boundary layer growth due to this 'numerical viscosity'. Physical viscosity was later applied to simulate different Reynolds numbers, as discussed at the end of Section 4. The 2-D approximation of LES (Section 2.4) was applied to the flow outside the nozzle in order to properly simulate the free jet. The calculation for the nozzle's internal flow should be deemed more relevant in the present study.

The computed domain started at the inlet of the convergent section of the nozzle as shown in figure 2 . The domain extended over a rectangular subdomain outside the nozzle (21.5 inch in axial direction x 16 inch in radial direction; see figure 3). The computation was started with the entire flow at rest and with the desired plenum

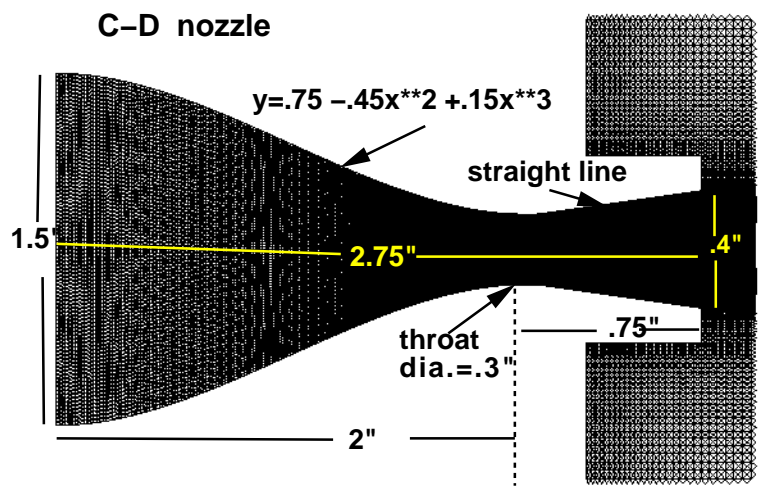

Figure 2: Geometry of the C-D nozzle and unstructured grid

pressure applied at the inlet boundary. A no-slip boundary condition was imposed on the nozzle wall. For the outer subdomain, ambient conditions were applied at the upstream inflow boundary, non-reflective conditions were applied at the upper and downstream boundaries, while a mirror-image reflective (symmetry axis) condition was applied at the bottom boundary.

The geometry of the nozzle can be seen in figure 2 . The inlet diameter is 1.5 ". The diameters at the nozzle's throat and exit are respectively $D_{t}=0.3$ " and $D_{e}=$ 0.4 ". The throat is located 2 " downstream of the inlet. The convergent part follows a curved contour $r=f(x)$ as noted in the figure, while the contour of the divergent part is a straight line. The geometry corresponds to Case ' $3 T 2$ ' described in [1].

In the experiments it has been shown that the origin of the resonance is internal to the nozzle (unlike screechtones). Thus, the numerical investigation concentrates on the interior flow of the nozzle and the near field. Furthermore, the flow and the acoustic fields have been found to be of the axisymmetric mode in the experiments. Hence, the axisymmetric CE/SE code has been deemed sufficient, at least as a first attempt, in computing the flow. The ambient flow around the nozzle is assumed stationary.

For convenience, $a=1$ " is chosen as the length scale. (However, the throat-to-exit length, $L=0.75$ ", is used to nondimensionalize data in some of the figures to be commensurate with the experiment.) The computational domain is a circular cylinder of $24.5 a$ long and $16 a$ in radius. The unstructured grid is formed by cutting a rectangular cell into 4 triangles ). These rectangular cells are non-uniform and their numbers in the $x$ and $y$ directions are 200 and 225, respectively. In a typical case, total number of triangles is 114,000 . The last 10 cells in the streamwise direction have exponentially growing $x$ size and serve as a buffer zone to ensure no numerical reflec- 


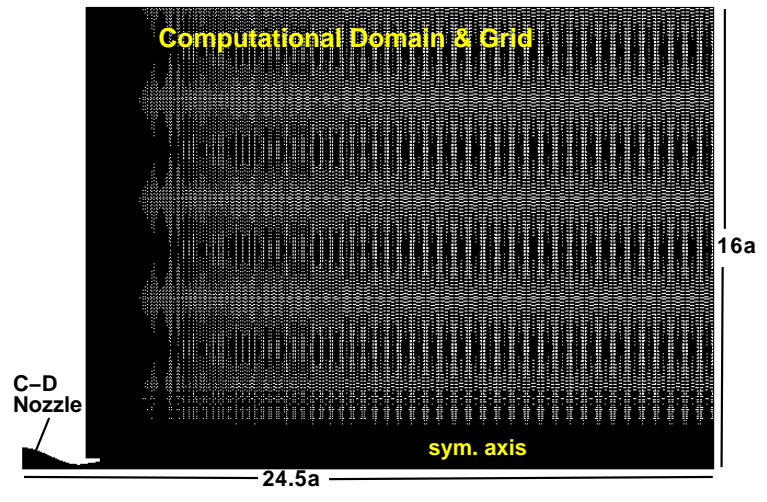

Figure 3: Geometry of the entire computational domain and unstructured grid.

tion from the outflow boundary. The grid resolution was deemed sufficient since a coarser grid produced the same results as discussed shortly. The CE/SE scheme is of the $a-\epsilon$ type $[3,4]$ with $\alpha=0$ and $\epsilon=0.5$.

\subsection{Initial Conditions}

The pressure $p_{i}$ and the speed of sound $a_{i}$ in the ambient flow are used to scale the dependent variables. Initially, the flow of the entire domain is set at the ambient conditions, i.e.,

$$
\rho_{i}=\gamma=1.4, \quad u_{i}=0, \quad v_{i}=0, \quad p_{i}=1
$$

Note that $p_{i}=1$ corresponds to a dimensional pressure of 14.4 psi in the experiments. Consequently, the conservative flow variables and their spatial derivatives can be obtained in an easy way. Initially, all spatial derivatives are set to zero.

\subsection{Boundary Conditions}

At the inflow boundary outside the nozzle, the conservative flow variables and their spatial derivatives are specified to be the same as the ambient flow. The inlet of the C-D nozzle is connected to the plenum which provides a constant pressure $p=p_{0}$ to drive the flow. According to the experimental conditions, 5 different $p_{0}$ values $(4,8,10,15$ and 20 psig) are chosen in the computation. The actual non-dimensional $p_{0}$ values are respectively $1.277778,1,555556,1.6944444,2.0416667$ and 2.3888889 .

Following the experimental condition, the temperature in the plenum is assumed to be equal to that in the ambient. By using the assumptions of constant total enthalpy and isentropic flow, it follows that the density $\rho_{i}$ at the nozzle inlet is related to the ambient pressure $p_{i}$ and density $\rho_{i}$ by

$$
\rho_{0}=\frac{p_{0}}{p_{i}} \rho_{i}
$$

Flow at the nozzle inlet is at rest:

$$
u_{0}=v_{0}=0 \text {. }
$$

No artificial forcing is imposed anywhere. As stated earlier, no slip condition is applied at the nozzle walls. At the symmetry axis, i.e. $y=0$, reflective boundary condition is applied. At the top and outflow boundaries, the Type I and Type II CE/SE non-reflecting boundary conditions as described in the next subsection are imposed respectively.

\subsection{Non-Reflecting Boundary Conditions}

In the $\mathrm{CE} / \mathrm{SE}$ scheme, non-reflecting boundary conditions (NRBC) are constructed so as to allow fluxes from the interior domain to a boundary $C E$ smoothly exit to the exterior of the domain. There are various variants of the non-reflecting boundary condition and in general they have proven to be well suited for aeroacoustic problems [5-7]. The following are the ones employed in this paper.

For a grid node $(j, n)$ lying at the outer radius of the domain the non-reflective boundary condition (type I) requires that

$$
\left(\boldsymbol{U}_{x}\right)_{j}^{n}=\left(\boldsymbol{U}_{y}\right)_{j}^{n}=0
$$

while $\boldsymbol{U}_{j}^{n}$ is kept fixed at the initially given steady boundary value. At the downstream boundary, where there are substantial gradients in the radial direction, the nonreflective boundary condition (type II) requires that

$$
\left(\boldsymbol{U}_{x}\right)_{j}^{n}=0
$$

while $\boldsymbol{U}_{j}^{n}$ and $\left(\boldsymbol{U}_{y}\right)_{j}^{n}$ are now defined by simple extrapolation from the nearest interior node $j^{\prime}$, i.e.,

$$
\boldsymbol{U}_{j}^{n}=\boldsymbol{U}_{j^{\prime}}^{n-1 / 2} \quad\left(\boldsymbol{U}_{y}\right)_{j}^{n}=\left(\boldsymbol{U}_{y}\right)_{j^{\prime}}^{n-1 / 2} .
$$

As will be observed later, these NRBCs are robust enough to allow a near field computation without disturbing or distorting the flow and acoustic fields.

\section{Results}

The calculations were carried out until a 'limit cycle' oscillation in the flow field was reached. At this state the flow property at a given point in the computational domain would undergo a quasi-periodic oscillation with varying time. The pressure oscillation at a given point in the computational domain for the $p_{0}=1.694$ (10 psig) case is shown in figure 4 . The underlying periodicity in the time history should be apparent upon an inspection. The power spectrum corresponding to the data of figure 4 , shown in figure 5 , illustrates the periodicity unambiguously. The spectrum is clearly characterized by a peak at a frequency of about $2600 \mathrm{~Hz}$. A large number of time steps $(410,000$ to 740,000$)$ had to be run in order to 


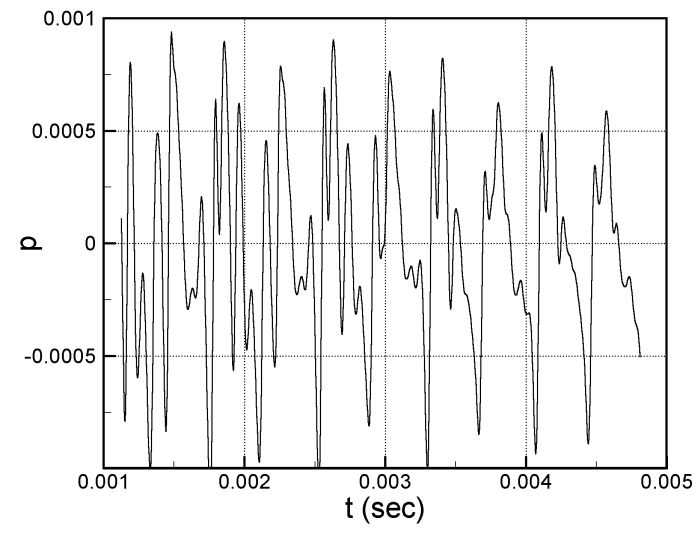

Figure 4: Time history of pressure fluctuation at $\mathrm{x} / \mathrm{L}=$ $0.667, \mathrm{y} / \mathrm{L}=2.66$.

achieve appropriate resolution on the low frequency end of the spectrum.

Also shown in figure 5 is the power spectrum density (PSD) calculated at approximately the same location using a coarser grid (80,000 cells). The amplitude of the peak is somewhat different from that for the fine grid. This is not unexpected since the phenomenon is not exactly periodic and the physical locations are not exactly the same. However, it is clear that the frequency of the peak is the same. Thus, the fine grid resolution $(114,000$ cells) may be considered adequate.

The oscillation could be detected basically everywhere in the computational domain (although in regions corresponding to 'nodes' the pressure oscillation might not be clear). The p'-spectrum obtained from data at a different point is shown in figure 6, as another example. Except for some difference in the higher frequency peaks the overall spectrum and the dominant peak remains unchanged. Note that the data in figure 5 represent near-field acoustic pressure (outside the nozzle) whereas those in figure 6 represent pressure oscillation within the core of the flow. The flow oscillation frequencies are determined in a similar manner through spectral analysis for all five operating pressures. These frequencies are compared with experimental data in figure 7 .

Here, let us first briefly summarize the experimental results (Zaman et al. [1]). The frequency data were obtained by spectral analysis of a microphone signal. The data include 'screech' tones as well as the 'transonic tones', as marked in the figure. The latter phenomenon is the subject under consideration. Note that there is a staging behavior with the transonic tones. Two stages, marked in the figure, are detected with the nozzle under consideration. From an analysis of data from a large number of nozzles, it was inferred that stage (1) repre-

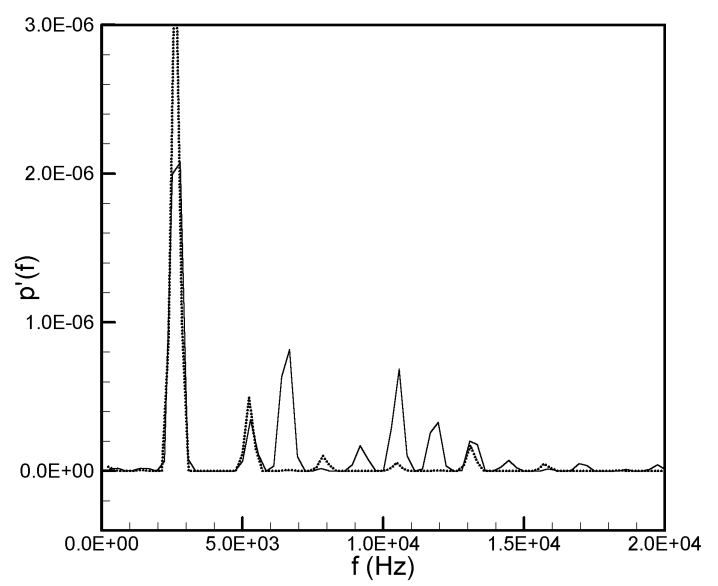

Figure 5: Power spectral density of fluctuating pressure at $\mathrm{x} / \mathrm{L}=0.667, \mathrm{y} / \mathrm{L}=2.66$. Solid line: fine grid $(114,000$ cells), dotted line: coarse grid (80000 cells).

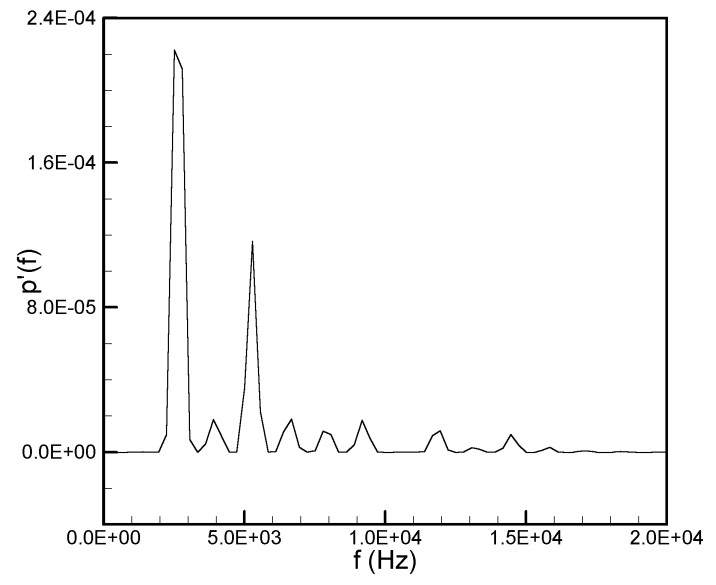

Figure 6: Power spectral density of fluctuating pressure within the convergent section at $\mathrm{x} / \mathrm{L}=-0.667, \mathrm{y} / \mathrm{L}=0.20$. 


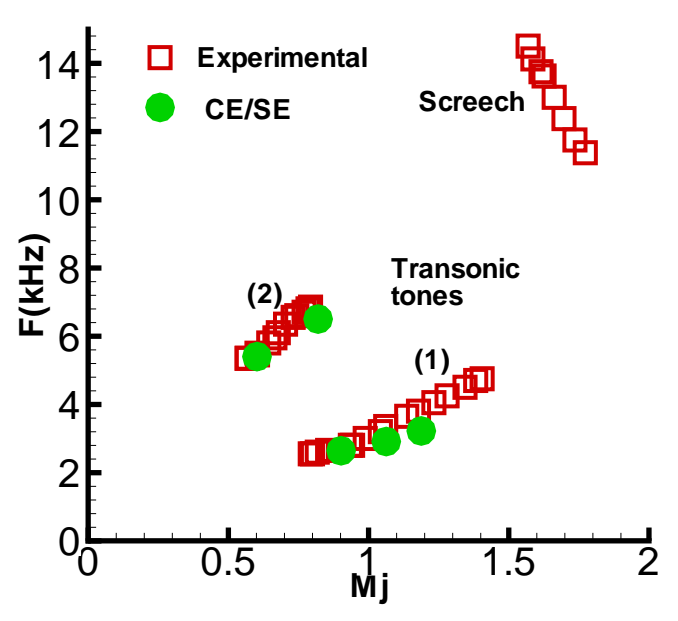

Figure 7: Variation of tone frequency with $M_{j}$. Open symbols: experimental data (for nozzle 3T2; Zaman et al. [1]), Solid symbols: present numerical results.

sented the fundamental in the resonance while stage (2) represented the next odd (3rd) harmonic. It was found that the presence of a shock within the upstream reaches of the divergent section was a necessary condition for the resonance to take place. A physical model for the underlying mechanism was proposed. In short, the unsteady shock was thought to act like a vibrating diaphragm and resonance took place in a manner similar to that occurring in the simple (no-flow) acoustic resonance of a conical section with one end open and the other end closed. Thus, the fundamental was expected to involve a onequarter (wavelength) standing wave within the diverging section while the next (third) harmonic (stage 2) was expected to involve a three-quarter standing wave. Unsteady flow measurements did indicate the presence of such standing waves. However, the latter observation was not on firm ground because of the possibility of probe interference effects.

In figure 7, the numerical results for the resonant frequencies are shown by the solid symbols. The results agree with the experimental data very well. Not only the trend of frequency variation within each stage, and the stage jump, are captured but also the frequencies are predicted quite well.

Details of the flow field were computed for two pressures, $p_{0}=1.278$ and 1.694 , corresponding to stage (2) and stage (1) resonance, respectively. The static pressure distributions are shown in figure 8 for the fundamental case at $p_{0}=1.694$. The 11 frames span approximately $2 \mathrm{~T}$, $\mathrm{T}$ being the period of the oscillation. Thus, approximately on the 6th frame the period is completed and a similar distribution is expected as in the 1st frame. This

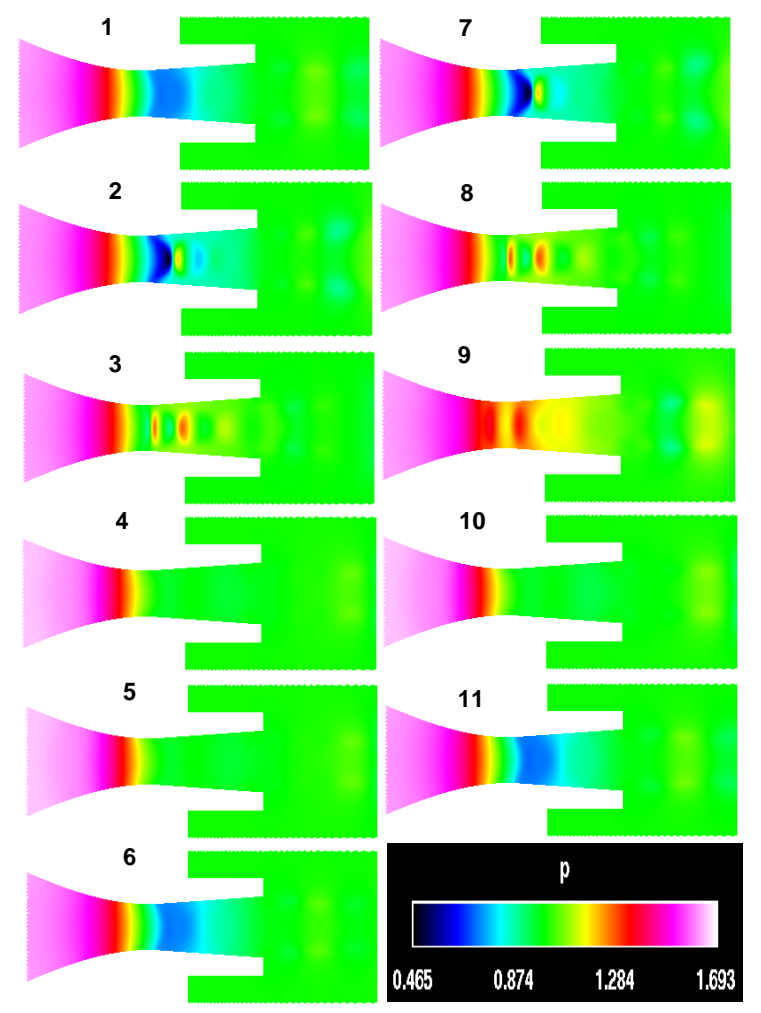

Figure 8: Detailed flow-field pressure data for the fundamental case at 10 psig (stage 1 ).

is indeed the case as can be seen. Numerical Schlieren pictures (i.e., distributions of $\frac{\partial \rho}{\partial x}$ ), corresponding to the instants of figure 8 , are shown in figure 9. These illustrate the unsteady shock structure and its motion within the period. A shock (denoted by the boundary between the yellow/red and blue/green regions) can be seen past the throat of the nozzle. The shape and structure of the shock changes widely over the period. During part of the cycle, a clear 'bow-shaped' front is seen (frames 1,6). During other parts of the cycle a 'lambda-shock' is seen clearly (frame 2,7). Yet during other parts of the cycle, multiple fronts are noted. Corresponding distributions of the axial velocity $(\mathrm{U})$ are shown in figure 10 . A flow separation downstream of the throat of the nozzle can be observed. The length of the separated flow region changes over the period.

Flow field details for the $p_{0}=1.278$ (stage 2) case are shown in figures 11-13, in a similar manner as in figures 8-10. Here, an approximate repetition of the flow pattern every sixth frame can also be observed. However, it is not as clear as in the case of the fundamental. In any case, the completion of the period can be inferred, for example, by following the yellow patch of high-pressure region to the right of the nozzle exit in figure 11. It propagates downstream with increasing time step, until in the sixth 


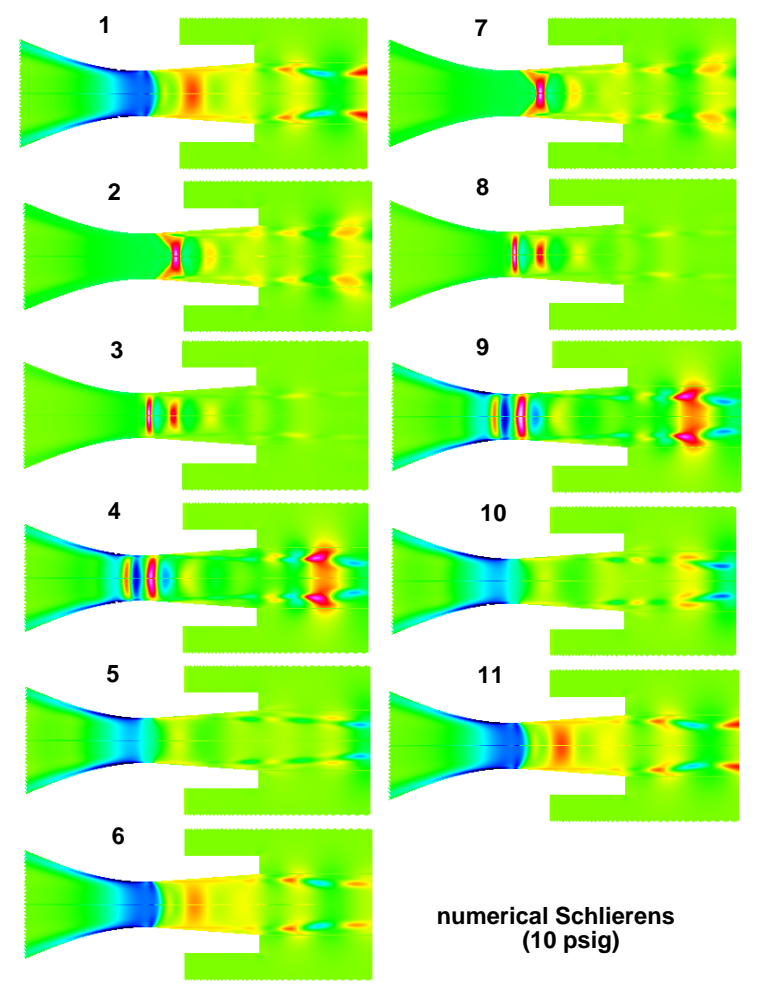

Figure 9: Detailed numerical Schlieren data for the fundamental case at $10 \mathrm{psig}($ stage 1$)$.

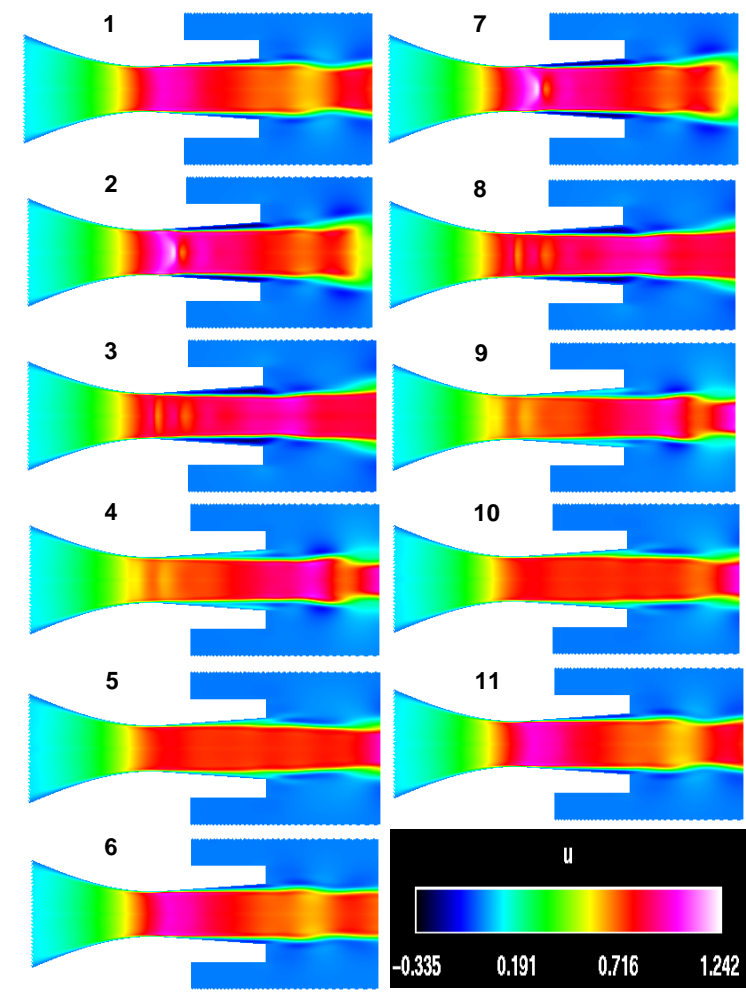

Figure 10: Detailed flow-field u-velocity data for the fundamental case at 10 psig (stage 1$)$.

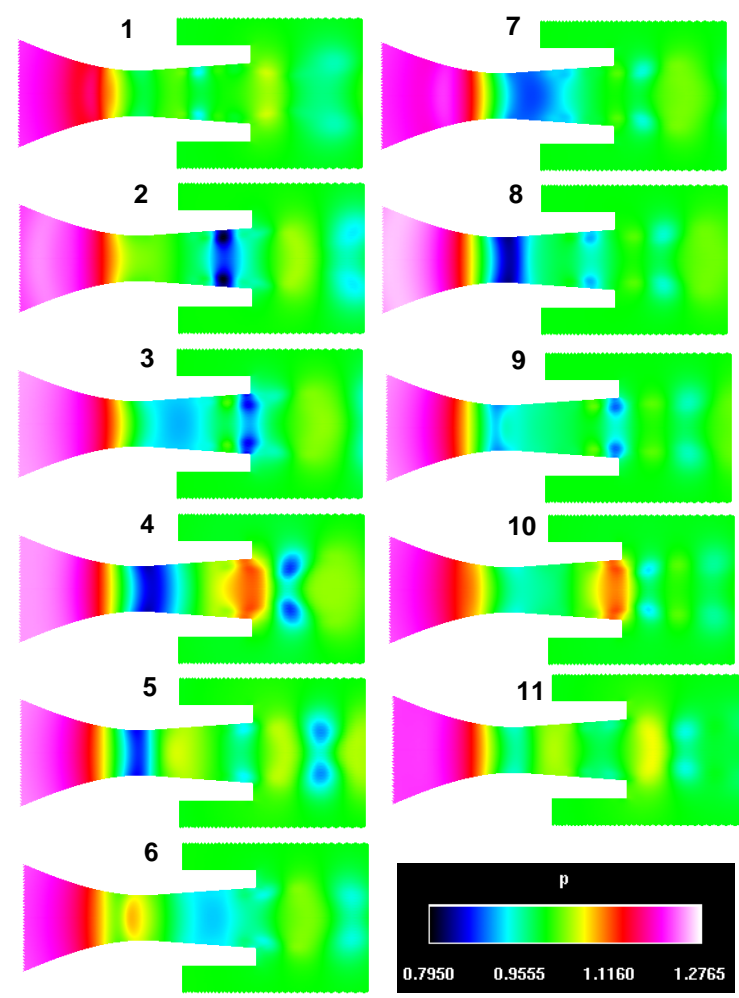

Figure 11: Detailed flow-field pressure data for the case at 4 psig (stage 2).

frame a pattern similar to that in frame 1 reappears.

Referring back to the Schlieren pictures for the $p_{0}$ $=1.694$ case, a qualitatively similar shock motion may be noted in past experimental investigations. The Schlieren pictures in figure 14 are from the experiment of C.A. Hunter of NASA Langley Research Center for a 2-D convergent- divergent nozzle (see Hunter 1998 [10], and Zaman et al. [1] for further details). Compare for example, the pictures in figures 14(a), (b) and (c) with frames 1,2 and 4 of figure 9.

The r.m.s. pressure fluctuation amplitudes were computed from the data on the centerline of the nozzle. The results are shown in figures 15(a) and (b) for the cases of the 3rd harmonic (stage 2) and fundamental (stage 1), respectively. The throat is located at an abscissa value of 0 while the nozzle exit is at 1 . First, in figure 15(b), it can be noted that there is a pressure anti-node somewhat downstream of the throat while a node exists somewhat downstream of the exit. This clearly indicates the presence of a one-quarter standing wave within the divergent section. Similarly, a three-quarter standing wave is observed for stage (2) in figure 15(a). The results of figure 15 agree with and confirm the presence of the standing waves that were conjectured from experimental evidence, as discussed earlier. 

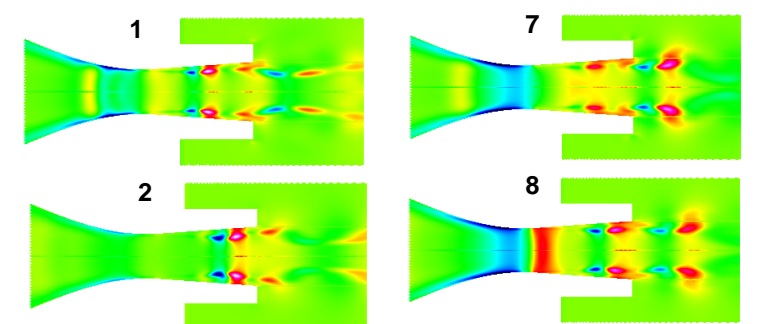

3

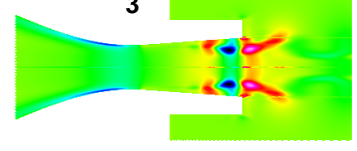

4

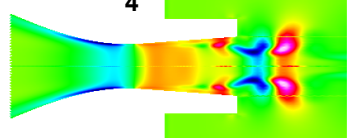

5

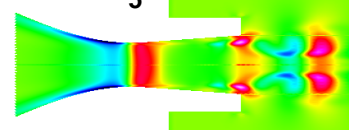

6

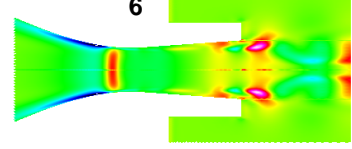

Numerical Schlieren

Figure 12: Detailed numerical Schlieren data for the case at 4 psig (stage 2).
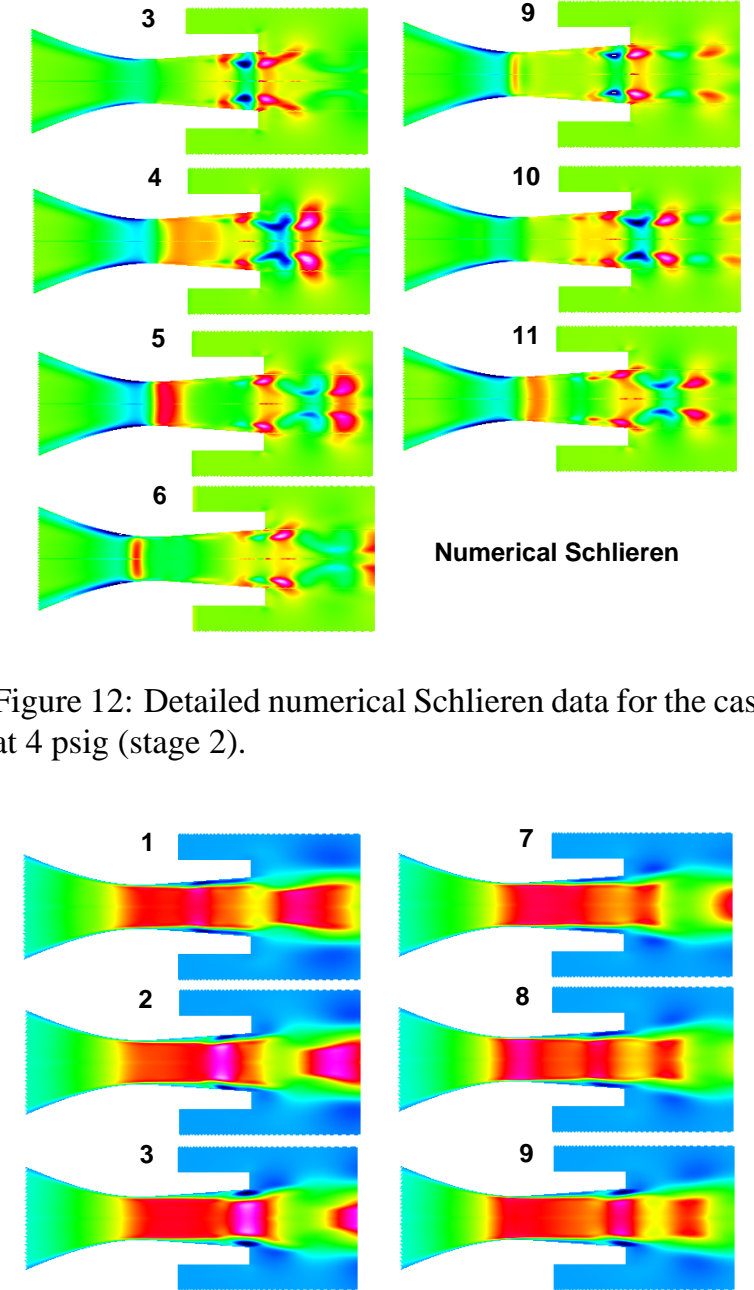

4

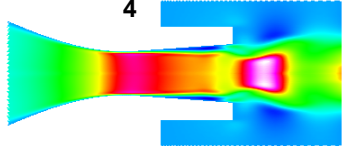

5

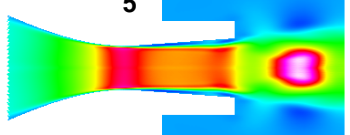

6
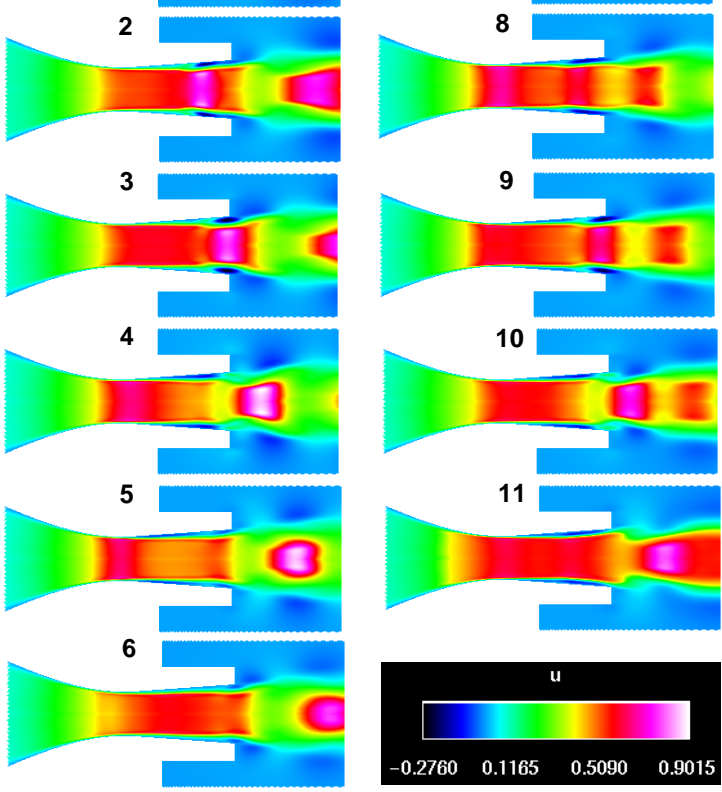

9
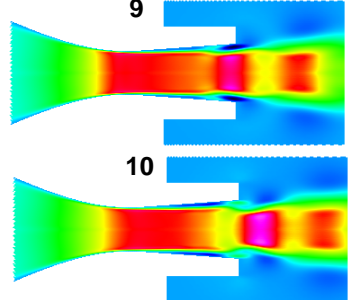

11
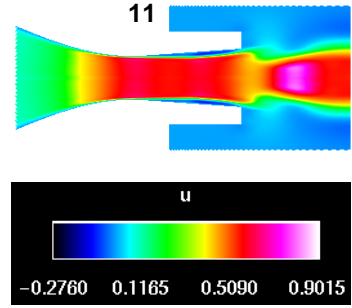

Figure 13: Detailed flow-field u-velocity data for the case at 4 psig (stage 2).

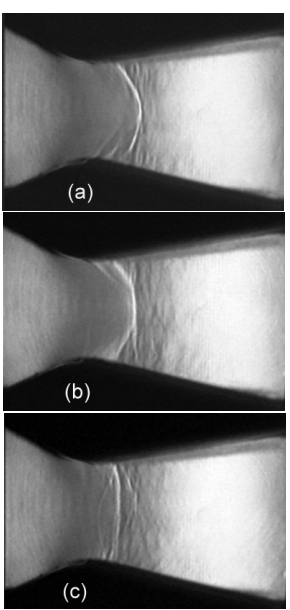

Figure 14: Schlieren pictures of the internal shock structure for fundamental resonance at $\mathrm{Mj}=0.71$ for a rectangular nozzle, from the experiment of Hunter [10].

A recent experimental investigation in connection with flow metering using Venturi nozzles [11] is worth mentioning here. In this work, flow unsteadiness was observed at relatively low pressure-ratios. Time-averaged data on 'recovery temperature' clearly exhibited the presence of one-quarter, three-quarter and even five-quarter standing waves within the divergent section. (In private communication, the first author of [11] confirmed that the flows were accompanied by emission of tones. Unfortunately, frequencies were not measured that would have allowed a comparison with the correlation equations of Ref. 1 and a determination if the unsteadiness was indeed the same phenomenon as studied here.)

In figure 16, the pressure amplitudes are shown for the fundamental case at a given instant. The acoustic radiation pattern at the resonance frequency is captured in this plot. It is noteworthy that the pattern is similar to that observed with duct acoustic resonance. For example, in the work of [12] the pressure fluctuations for a resonating cylindrical duct were calculated. While the internal pressure amplitudes apparently showed standing waves (their Fig. 13), the external radiation pattern appeared similar to that observed here.

Finally, the effect of Reynolds number is examined on the resonance frequency. In the experiments the resonance tended to disappear with increasing pressure ratio (or $M_{j}$ ). Thus, the highest pressure-ratio ( $20 \mathrm{psig}$ case) was chosen for this Reynolds number sensitivity study. Computations were performed for three additional Reynolds numbers, calculated on the basis of acoustic speed in the ambient and a length-scale of $1 \mathrm{inch}$. The solid curve, representing 'high Re' calculation was obtained in the same way as described above (by setting $\mu$ to zero; see Section 3). This involved boundary layer 
with growth only due to 'numerical viscosity'. The latter depends on grid size and other parameters of the computational procedure. An estimate of the numerical viscosity is not straightforward, however, the corresponding Reynolds number is thought to be quite high. The lower Reynolds number cases were obtained by setting correspondingly higher values of $\mu$. Note that the nominal Reynolds number based on molecular viscosity is about 600,000 .

The power spectral density of the fluctuating pressure is shown in Fig. 17. For brevity, these calculations were performed only for limited lengths of time so that the resolution in Fig. 17 is not as refined as in Figs. 5 and 6. The ordinate in Fig. 17 has a $\log$ scale and thus the higher harmonics appear prominently. It is clear that the resonance persists over a wide range of Reynolds numbers and for high and moderate Re's, their effect on the resonance frequency is quite small (about $2 \%$ at maximum). Only at the lowest $\mathrm{Re}$ the oscillation disappears. Note that a deceasing $\operatorname{Re}$ is equivalent to a thickening of the boundary layer. The trend is therefore consistent with experimental observation that the resonance is suppressed upon tripping of the boundary layer. However, the exact mechanism of the tripping effect remains unclear [1] and further study, including computational, is needed to obtain a full understanding.

\section{Discussion and Summary}

It is important to discuss certain past work that addressed the same or similar unsteady phenomenon. In the work reported in [13], a simulation of the experiments of [14] was performed. The experiment [14] reported a periodic unsteady flow through a two-dimensional 'transonic diffuser'. The floor of the diffuser was flat, the two side-walls were parallel and the top wall was convergentdivergent. An examination of the frequency data from this experiment (see Ref. [1] for full discussion), led to the inference that the observed unsteadiness must be of same morphology as of the subject phenomenon. Of relevance here is the fact that the numerical simulation of [13] appeared to have captured the flow unsteadiness quite well. A two-dimensional, compressible, Reynolds-averaged Navier-Stokes (RANS) solver was used together with a two-equation turbulence model. The computation was started with an initial state determined from quasi-one-dimensional analysis. After sufficient time steps the flow settled into an oscillatory pattern. The period of oscillation for some of the cases agreed well with the data of [14]. However, it was found that the diffuser flow field and the frquency were very sensitive to the location of the downstream boundary.

Another numerical work [15] brought to the authors' attention also merit a discussion. This work concerned flow metering using Venturi nozzles. Numerical simu-
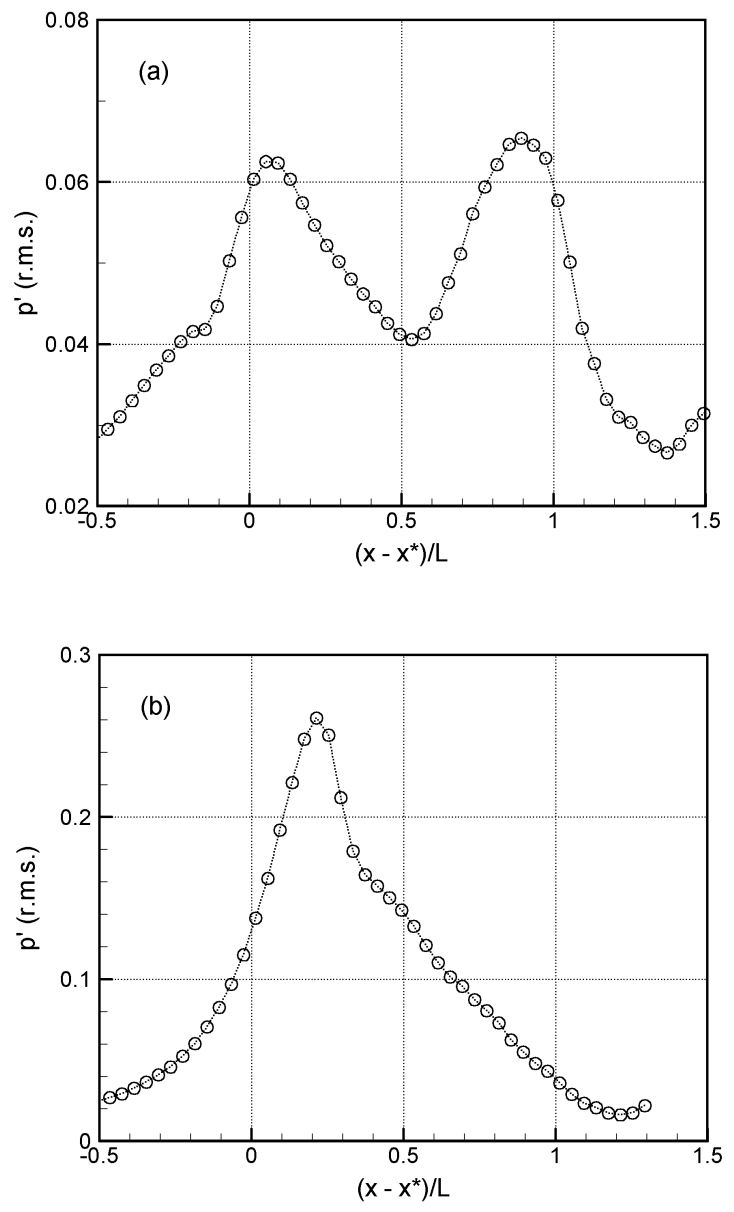

Figure 15: Time-averaged (r.m.s.) amplitude of fluctuating pressure along centerline of nozzle; (a) $p_{0}=1.278$ case (stage 2 ); (b) $p_{0}=1.694$ case (stage 1 ). 
lation was conducted for flows similar to that of [11], discussed in connection with Fig. 15. An axisymmetric, unsteady, compressible Navier-Stokes solver was used. For certain conditions, a quasi-periodic fluctuation was observed in the computed flow field. From the data provided in [15] it was not possible to determine if the frequencies followed the correlation equations of [1]. However, the symptoms appeared similar and the unsteadiness seemed likely to be of the same origin as the transonic resonance.

Thus, to the authors' knowledge, at least two past numerical works also likely captured the transonic resonance phenomenon. The apparent ability to capture the phenomenon by 'any' unsteady code is surprising because experimentally it is known to be very sensitive to operating conditions especially to perturbations in the upstream boundary layer (see discussion of Fig. 17). Except for the similarity that all three simulations (present, [13] and [15]) involved axisymmetric or twodimensional codes, different algorithms and procedures were followed. The upstream boundary layer in the present simulation was 'laminar', that in [13] was apparently turbulent. We move on by noting that many aspects of the phenomenon, e.g., the effect of boundary layer tripping, have remained far from completely understood. Further numerical study has the promise of advancing the understanding, and this is planned for the future. Following is a summary of the results presented in this paper.

The unstructured CE/SE Navier-Stokes/Euler solver is applied to the transonic resonance phenomenon. It is clear that the essence of the phenomenon is captured by the computation. The frequency of the resonance and its variation with pressure-ratio, including a stage jump, are captured quite well. A significant contribution of the present study is the results clearly showing the characteristic standing waves (Fig. 15). This confirmed that the underlying mechanism is similar to that of acoustic (no-flow) resonance of a duct having one end open and the other closed. This was conjectured in the earlier experimental work [1] but the standing waves could not be measured with confidence because of probe interference.

The success in capturing the characteristics of the phenomenon attests to the validity of the numerical scheme. Other advantages of the CE/SE scheme include the 'effortless' implementation (no special treatment, grid refinement, etc.), the simple but effective NRBC and its shock-capturing capability.

As stated in Section 3, most of the results in this paper were obtained by 'inviscid' calculations for the internal flow. It can be viewed as a Navier-Stokes solution at a high Reynolds number with under-resolved boundary layer; the computed flow involved a boundary layer due to numerical viscosity only. Boundary layer separation following the shock can be observed in figures 10 and 13 .

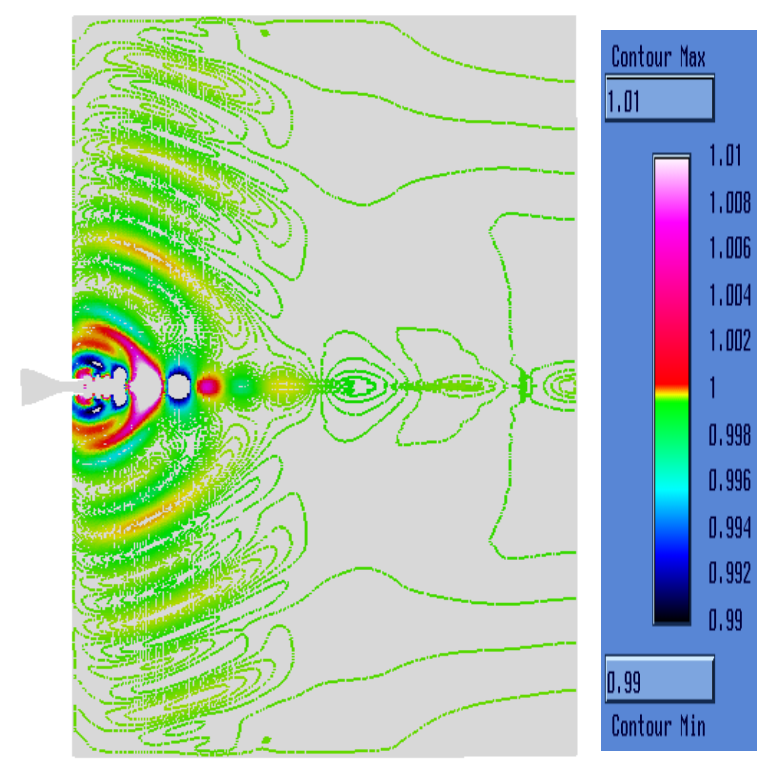

Figure 16: Acoustic radiation for the fundamental case. (10 psig)

However, one may not expect that the details of the separated flow and the separation bubble would be captured faithfully by such a procedure. On the other hand, users of the CE/SE method have demonstrated its capability to capture shock structure relatively faithfully. Thus, one may infer that the shock and its unsteadiness, possibly due to flow separation, are the primary ingredients of the transonic resonance phenomenon and that the exact details of the separated boundary layer are here relatively unimportant.

\section{References}

[1] Zaman, K.B.M.Q., Dahl, M.D. and Bencic, T.J. "Experimental Investigation of "Transonic Resonance' with Convergent-Divergent Nozzles", AIAA Paper 2001-0078 (2001).

[2] Chang, S. C., "The Method of Space-Time Conservation Element and Solution Element-A New Approach for Solving the Navier-Stokes and Euler Equations," J. Comput. Phys, vol. 119, pp. 295-324 (1995).

[3] Chang, S.-C., Wang, X.-Y. and Chow, C.-Y., "The Space-Time Conservation Element and Solution Element Method-A New High Resolution and Genuinely Multidimensional Paradigm for Solving Conservation Laws," J. Comp. Phys., vol. 159, pp. 89-136 (1999). 


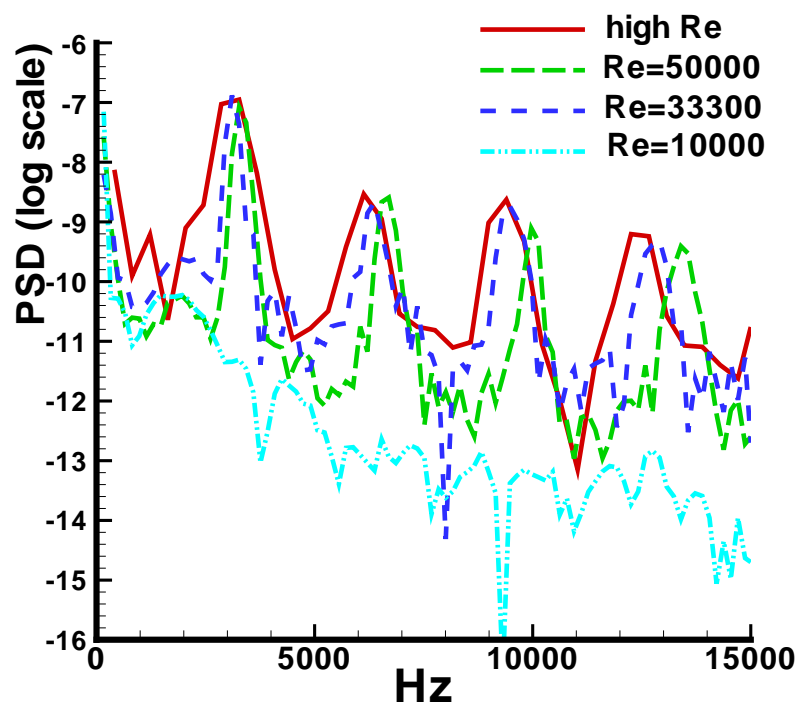

Figure 17: Power spectral density of fluctuating pressure at $x / L=.667, y / L=2.667$, showing the influence of Reynolds number Re (20 psig case).

[4] Wang, X.-Y. and Chang S.-C., " A 2-D Nonsplitting Unstructured Triangular Mesh Euler Solver Based on the Space-Time Conservation Element and Solution Element Method" C.F.D. J., vol. 8, pp. 309-325 (1999).

[5] Loh, C. Y., Hultgren, L. S. and Chang S.-C., "Computing Waves in Compressible Flow Using the Space-Time Conservation Element Solution Element Method," AIAA J., vol. 39, pp. 794-801 (2001); also AIAA Paper 98-0369 (1998).

[6] Loh, C. Y., Hultgren, L. S., Chang, S.-C. and Jorgenson, P. C. E., "Vortex Dynamics Simulation in Aeroacoustics by the Space-Time Conservation Element Solution Element Method," AIAA Paper 990359 (1999).

[7] Loh, C. Y., Hultgren, L. S., and Jorgenson, P. C. E., "Near Field Screech Noise Computation for an Underexpanded Supersonic Jet by the CE/SE Method," AIAA Paper 2001-2252 (2001).

[8] Chang, S.-C., Himansu, A., Loh, C. Y., Wang, X. Y., Yu, S.-T. and Jorgenson, P. C. E. "Robust and Simple Non-Reflecting Boundary Conditions for the Space-Time Conservation Element and Solution Element Method", AIAA Paper 97-2077 (1997).
[9] Bogey, C., Bailly, C. and Juvé, D., "Computation of the Sound Radiated by a 3-D Jet Using Large Eddy Simulation," AIAA Paper 2000-2009 (2000).

[10] Hunter, C.A., "Experimental, Theoretical, and Computational Investigation of Separated Nozzle Flows", AIAA Paper 98-3107 (1998).

[11] Ishibashi, M. and Takamoto, M., "Discharge coefficients of critical nozzles with step near the throat and their flow field estimated from recovery temperature distribution", FEDSM2001-18035, ASME Fluids Engineering Division Summer Meeting, New Orleans, LA. (2001).

[12] Hu, F.Q. and Manthey, J.L., "Application of PML absorbing boundary conditions to the benchmark problems of computational aeroacoustics", NASA CP 3352, Second CAA Workshop on benchmark problems, edited by C. K. W. Tam and J. C. Hardin, June 1997.

[13] Hsieh, T. and Coakley, T.J., ’Downstream boundary effects on frequency of self-excited oscillations in transonic diffuser flows," AIAA Paper 87-0161, 25th Aerospace Sciences Meeting, Reno, NV, Jan. 12$15,1987$.

[14] Bogar, T.J., Sajben, M. and Kroutil, J.C., "Characteristic frequencies of transonic diffuser flow oscillations," AIAA J., 21 (9), pp. 1232-1240., 1983.

[15] von Lavante, E. Zaichcial, A., Nath, B. and Dietrich, H., "Numerical and experimental investigation of unsteady effects in critical Venturi nozzles", Flow measurement and instrumentation, vol. 11, pp. 257-264, 2000. 


\begin{tabular}{|c|c|c|}
\hline \multicolumn{2}{|c|}{ REPORT DOCUMENTATION PAGE } & $\begin{array}{l}\text { Form Approved } \\
\text { OMB No. 0704-0188 }\end{array}$ \\
\hline \multicolumn{3}{|c|}{$\begin{array}{l}\text { Public reporting burden for this collection of information is estimated to average } 1 \text { hour per response, including the time for reviewing instructions, searching existing data sources, } \\
\text { gathering and maintaining the data needed, and completing and reviewing the collection of information. Send comments regarding this burden estimate or any other aspect of this } \\
\text { collection of information, including suggestions for reducing this burden, to Washington Headquarters Services, Directorate for Information Operations and Reports, } 1215 \text { Jefferson } \\
\text { Davis Highway, Suite 1204, Arlington, VA 22202-4302, and to the Office of Management and Budget, Paperwork Reduction Project (0704-0188), Washington, DC 20503. }\end{array}$} \\
\hline 1. AGENCY USE ONLY (Leave blank) & $\begin{array}{l}\text { 2. REPORT DATE } \\
\text { January } 2002\end{array}$ & $\begin{array}{l}\text { D DATES COVERED } \\
\text { echnical Memorandum }\end{array}$ \\
\hline \multicolumn{2}{|c|}{$\begin{array}{l}\text { Numerical Investigation of "Transonic Resonance" With a } \\
\text { Convergent-Divergent Nozzle }\end{array}$} & 5. FUNDING NUMBERS \\
\hline \multicolumn{3}{|c|}{ Ching Y. Loh and K.B.M.Q. Zaman } \\
\hline $\begin{array}{l}\text { 9. SPONSORING/MONITORING AGEI } \\
\text { National Aeronautics and Sp } \\
\text { Washington, DC 20546-00 }\end{array}$ & $\begin{array}{l}\text { NAME(S) AND ADDRESS(ES) } \\
\text { Administration }\end{array}$ & $\begin{array}{l}\text { 10. SPONSORING/MONITORING } \\
\text { AGENCY REPORT NUMBER } \\
\text { NASA TM-2002-211324 } \\
\text { AIAA-2002-0077 }\end{array}$ \\
\hline
\end{tabular}

\section{SUPPLEMENTARY NOTES}

Prepared for the 40th Aerospace Sciences Meeting and Exhibit sponsored by the American Institute of Aeronautics and Astronautics, Reno, Nevada, January 14-17, 2002. Ching Y. Loh, Taitech Inc., 21000 Brookpark Road, Cleveland, Ohio 44135; and K.B.M.Q. Zaman, NASA Glenn Research Center. Responsible person, K.B.M.Q. Zaman, organization code $5860,216-433-5888$.

12a. DISTRIBUTION/AVAILABILITY STATEMENT 12b. DISTRIBUTION CODE

Unclassified - Unlimited

Subject Categories: 02, 64 and 71

Distribution: Nonstandard

Available electronically at http://gltrs.grc.nasa.gov/GLTRS

This publication is available from the NASA Center for AeroSpace Information, 301-621-0390.

13. ABSTRACT (Maximum 200 words)

At pressure ratios lower than the design value, convergent-divergent (C-D) nozzles often undergo a flow resonance accompanied by the emission of acoustic tones. The phenomenon, driven by the unsteady shock within the divergent section of the nozzle, has been studied experimentally by Zaman et al. In this paper, the space-time conservation element solution element (CE/SE) method is employed to numerically investigate the phenomenon. The computations are performed for a given nozzle geometry for several different pressure ratios. Sustained 'limit cycle' oscillations are encountered in all cases. The oscillation frequencies, their variation with pressure ratio including a 'stage jump', agree well with the experimental results. The unsteady flow data confirm that stage 1 of the resonance (fundamental) involves a onequarter standing wave while stage 2 (third harmonic) involves a three-quarter standing wave within the divergent section of the nozzle. Details of the shock motion, and the flow and near acoustic field, are documented for one case each of stages 1 and 2 .

14. SUBJECT TERMS

Transonic resonance; C-D nozzle; CE/SE method
15. NUMBER OF PAGES

18

16. PRICE CODE

\begin{tabular}{|c|c|c|}
\hline $\begin{array}{c}\text { 17. SECURITY CLASSIFICATION } \\
\text { OF REPORT } \\
\text { Unclassified }\end{array}$ & $\begin{array}{c}\text { 18. SECURITY CLASSIFICATION } \\
\text { OF THIS PAGE } \\
\text { Unclassified }\end{array}$ & $\begin{array}{c}\text { 19. SECURITY CLASSIFICATION } \\
\text { OF ABSTRACT } \\
\text { Unclassified }\end{array}$ \\
\hline
\end{tabular}

NSN 7540-01-280-5500

Standard Form 298 (Rev. 2-89) 